\title{
PENGARUH LAYANAN BIMBINGAN KELOMPOK DENGAN TEKNIK MODELLING SIMBOLIK UNTUK MENINGKATKAN KEDISIPLINAN
}

\author{
Muhammad Rizal P.L.K ${ }^{1}$, Yovitha Yuliejantiningsih ${ }^{2}$, Tri Hartini $^{3}$ \\ ${ }^{1,2,3}$ Program Studi Bimbingan dan Konseling, Fakultas IImu Pendidikan, \\ Universitas PGRI Semarang \\ e-mail: rizalplk7@gmail.com
}

\begin{abstract}
ABSTRAK
Penelitian ini bertujuan untuk mengetahui pengaruh layanan bimbingan kelompok dengan teknik modelling simbolik untuk meningkatkankan kedisiplinan pada siswa. Jenis penelitian ini adalah penelitian kuantitatif melalui metode penelitian true experimental design dengan model pre-test posttest control group design. Populasi dalam penelitian ini adalah 107 siswa. Sampel dalam penelitian yaitu 30 siswa kelas X SMK 01 Muhammadiyah Semarang yang diambil dengan menggunakan teknik Cluster random sampling. Alat pengumpul data yang dipergunakan adalah skala kedisiplinan. Berdasarkan hasil analisis uji hipotesis diperoleh hasil thitung $=4,89$. Selanjutnya dikonsultasikan dengan ttabel dengan taraf signifikansi $5 \%(0.05)$ yaitu 2,131. Hal tersebut menunjukkan bahwa thitung $=4,89>$ ttabel $=2,131$. Atas dasar perhitungan tersebut maka hipotesis alternatif $(\mathrm{Ha})$ yang berbunyi "ada pengaruh layanan bimbingan kelompok dengan teknik modelling simbolik untuk meningkatkan kedisiplinan siswa kelas X SMK 01 Muhammadiyah Semarang tahun pelajaran 2018/2019" diterima kebenarannya pada taraf signifikansi 5\%. Dengan demikian menunjukkan bahwa layanan bimbingan kelompok dengan teknik modelling simbolik dapat meningkatkankan kedisiplinan siswa.
\end{abstract}

Kata Kunci : Bimbingan Kelompok, Teknik Modelling Simbolik, Kedisiplinan.

This study aims to determine the effect of group guidance services with symbolic modeling techniques to improve discipline in students. This type of research is quantitative research through true experimental design research methods with the model pre-test post-test control group design. The population in this study was 107 students. The sample in this study was 30 students of class $X$ SMK 01 Muhammadiyah Semarang taken using the Cluster random sampling technique. Data collection tool used is the scale of discipline. Based on the results of the analysis of the hypothesis test the results of tcount $=4.89$. Furthermore, it was consulted with a table with a significance level of $5 \%(0.05)$, namely 2.131. This shows that tcount $=4.89>t$ table $=2.131$. Based on these calculations, the alternative hypothesis $(\mathrm{Ha})$ which reads "there is an influence of group guidance services with symbolic modeling techniques to improve the discipline of class $X$ students of SMK 01 Muhammadiyah Semarang in the 2018/2019 academic year" is accepted at the 5\% significance level. Thus showing that group guidance services with symbolic modeling techniques can improve student discipline.

Keywords : Group Guidance, Symbolic Modeling Technique, Discipline 


\section{Pendahuluan}

Peningkatan mutu pendidikan merupakan masalah yang sangat esensial lebih-lebih berkenaan dengan upaya pengembangan dan peningkatan sumber daya manusia yang professional. Manusia yang professional adalah manusia yang menguasai ilmu pengetahuan dan teknologi serta manusia yang beriman dan bertaqwa. Banyak orang semakin sadar bahwa kunci utama kemajuan masayarakat ditentukan oleh pendidikan, sebab pendidikan adalah merupakan transformasi yang berfungsi membangun manusia yang berilmu pengetahuan, berteknologi dan bertaqwa. Oleh karena itu kemajuan tersebut dapat tercapai jika pendidikan harus berkualitas. Kualitas guru merupakan salah satu kunci yang dapat menentukan dan dapat mempengaruhi kualitas pendidikan. Sebagai orang yang berpengaruh besar terhadap karakter siswa, guru bukan sekedar bertugas untuk transfer of knowledge tetapi hal lain yang menjadi tugas guru adalah untuk transfer of value kepada peserta didik. Maka dari itu guru merupakan komponen utama yang perlu dikembangkan melalui berbagai macam kegiatan dalam rangka menambah pengetahuan dan keterampilan untuk menjadi tenaga yang professional dan memiliki kepribadian yang unggul. Guru bimbingan dan konseling sebagai orang yang patut untuk diteladani nampaknya masih banyak ditemukan sejumlah image negatif yang membawa citra dan nama baik guru BK di sekolah. Salah satunya adalah Guru BK sering dianggap sebagai polisi sekolah atau seksi keamanan sekolah. Menurut Sugiantoro (2011) menyatakan dalam surat kabar bahwa Fakta di lapangan, keberadaan Bimbingan dan Konseling (BK) di sekolah identik dengan masalah yang dihadapi siswa. Banyak siswa yang dianggap bermasalah diarahkan ke guru BK atau biasa disebut konselor untuk ditangani. Hal ini tidaklah salah, namun juga tak terlalu tepat. Ada kecenderungan guru BK ibarat polisi sekolah yang tugasnya menghukumi siswa bermasalah. Bahkan, siswa merasa tak nyaman berhubungan dengan guru BK, karena malu dan takut dianggap bermasalah oleh siswa-siswa lainnya. Koran Merapi, Selasa, 13 Desember 2011. Hal senada telah disampaikan oleh Kartadinata (2009) bahwa masalah pokok yang dihadapi guru bimbingan dan konseling di sekolah masih banyak layanan bimbingan konseling lebih merupakan kebutuhan formal daripada kebutuhan actual, tidak dan tidak jarang bahwa bimbingan dan konseling lebih merupakan pekerjaan administrative yang lebih menekankan bukti fisik dari pada sebagai pekerjaan professional (Sutanti, 2015).

Pada tahun 2000 UNESCO telah melakukan penelitian tentang Pendidikan, tentang peringkat indeks pengembangan manusia (human development indeks) yaitu komposisi dari peringkat pencapaian pendidikan, kesehatan, dan penghasilan perkepala yang menunjukkan bahwa indeks pengembangan manusia Indonesia makin menurun. Di antara 174 negara di dunia, Indonesia menempati urutan ke-102 pada 1996, ke-99 pada 1997, ke- 105 pada 1998, dan ke-109 pada 1999.dan bukti nyata yang lain tentang kemrosotan Pendidikan di Indonesia adalah terjadinya tawuran tingkat pelajar maupun mahasisiwa dan permasalahan kedisiplinan tingkat pelajar dan mahasiswa.

Pendidikan nasional dalam UU No.20 tahun 2002 pasal 3 yang bersangkuttan dengan system Pendidikan nasional yaitu berdasarkan tujuan pendidikan nasional, sekolah sebagai lembaga pendidikan yang formal mempunyai kebijakan tertentu yang dituangkan dalam bentuk aturan, salah satu aturan sekolah yang disebut tata tertib, atau lebih dikenal dengan disiplin sekolah.

Setiap instansi tidak pernah lepas dari yang namanya tata tertib dan peraturan yang harus dipatuhi, didalam kehidupan masyarakat peraturan juga diperlukan begitu pula disetiap sekolah. kepala sekolah,pegawai yang bekerja disekolah guru-guru, dan siswa-siswa juga diatur dalam sebuah peraturan. Maka untuk itu kita sebagai manusia yang senantiasa hidup dengan penuh peraturan harus lebih peduli terhadap aturan yang diberlakukan dimanapun kita berada, kita harus memiliki kedisiplinan yang baik, karena kunci dari kedisiplinan itu merupakan kesuksesan, maka dari itu mulai dari awal kita harus membiasakan diri peduli, serta patuh dan taat terhadap peraturan tata tertib yang berlaku di sekolah.

Bimbingan dan konseling terdapat beberapa layanan diantaranya adalah bimbingan kelompok. Didalam layanan bimbingan kelompok ada Pk (pemimpin kelompok) dan AK (anggota kelompok). Tugas $\mathrm{Pk}$ (pemimpin kelompok) adalah memimpin jalannya layanan 
bimbingan kelompok sedangkan AK (anggota kelompok) adalah anggota yang menjadi bagian dalam layanan bimbingan kelompok. Dalam layanan bimbingan dan kelompok beranggotakan 8-10 sisiwa yang membahas permasalahan umum.

Layanan bimbingan kelompok mampu mengarahkan siswa untuk lebih memiliki rasa tanggung jawab terhadap tugas dan kewajiban sebagai siswa. Salah satu wujud dari tanggung jawab adalah mematuhi peraturan dan tata tertib yang berlaku disekolah. Layanan bimbingan kelompok ada dua topik yaitu topik tugas dan topik umum. Topik tugas merupakan topik yang pembahasannya ditentukan oleh konselor, sedangkan topik bebas itu konselor memberi kebebasan untuk konseli mengungkapkan permaslahan yang umum.

Menurut Gibson dan Marianne (2011: 275), istilah bimbingan kelompok mengacu pada aktivitas-aktivitas kelompok yang berfokus pada penyediaan informasi atau pengalaman lewat aktivitas kelompok yang terencana atau terorganisir. Pelaksanaan bimbingan kelompok merupakan suatu kegiatan kelompok yang dilakukan oleh sekelompok orang dengan memanfaatkan dinamika kelompok. Selain itu. Selanjutnya Wibowo (2005: 17) mengemukakan bahwa bimbingan kelompok merupakan suatu kegiatan kelompok dimana pimpinan kelompok menyediakan informasi-informasi dan mengarahkan diskusi agar anggota kelompok menjadi lebih sosial atau untuk membantu anggota-anggota kelompok untuk mencapai tujuan-tujuan bersama Dalam Islam, bimbingan dan konseling merupakan bentuk bantuan yang bertujuan pada kemaslahatan. Bimbingan dan konseling Islami diberikan sebagai alternatif bagi pemecahan masalah kemanusiaan dan sosial yang semakin kompleks. Faqih (Dahlan, 2009: 1) mengatakan bahwa Bimbingan dan Konseling Islami adalah proses pemberian bantuan terhadap individu agar mampu hidup selaras dengan ketentuan dan petunjuk Allah sehingga dapat mencapai kebahagiaan hidup di dunia dan akhirat. Menurut Sutoyo (2009: 205) hakikat Bimbingan dan Konseling Islami ialah upaya membantu individu belajar mengembangkan fitrah-iman dan atau kembali kepada fitrah-iman dengan cara memberdayakan (empowering) fitrah-fitrah (jasmani, rohani, nafs, dan iman) agar fitrah-fitrah yang ada pada individu berkembang dan berfungsi dengan baik dan benar. Bimbingan dan Konseling Islami juga diartikan sebagai proses pemberian bantuan terarah, kontinu dan sistematis kepada individu agar dapat mengembangkan potensi atau fitrah beragama yang dimilikinya secara optimal dengan cara menginternalisasikan nilai-nilai yang terkandung di dalam al-Qur'an dan Hadits Rasulullah ke dalam dirinya, sehingga ia dapat hidup selaras dan sesuai dengan tuntunan alQur'an dan Hadits (Amin, 2010: 23). Merujuk kepada pengertian bimbingan kelompok secara umum dan pengertian bimbingan dan konseling Islami yang telah dijelaskan oleh beberapa ahli di atas, maka dapat dirumuskan bahwa bimbingan kelompok berbasis Islami adalah proses pemberian bantuan yang dilakukan oleh seorang ahli kepada individu melalui suasana kelompok dengan mengintegrasikan nilai-nilai yang terkandung di dalam ajaran Islam yang memungkinkan setiap anggota untuk belajar berpartisipasi aktif dan berbagi pengalaman dalam upaya pengembangan wawasan, sikap dan atau keterampilan yang diperlukan untuk mencegah timbulnya masalah atau pengembangan pribadi dalam rangka membantu individu hidup selaras dengan ketentuan dan petunjuk Allah sehingga dapat mencapai kebahagiaan hidup di dunia dan akhirat (Maulana, 2016).

Tanggung jawab sebagai siswa akan menunjukan kecintaannya pada sekolah, dengan selalu berusaha disiplin, baik dalam perbuatan dan perkataannya, semua ini akan tercermin dari cara berpakaian,cara berhadapan dengan guru,keseriusan dalam mengikuti mata pelajaran dengan baik. Disiplin merukapan masalah terbesar yang saat ini terjadi di Pendidikan Indonesia, permasalahan ini masih sangat sulit untuk di atasi dengan adanya kasus-kasus yang terjadi diantaranya adalah permaslahan sisiwa yang sering terlambat sekolah, belajar kalau ada ulangan saja, dan ada banyak tata tertib yang lain yang masih di laggar oleh sisiwa sekarang Tu'u (2004:29), mengemukakan bahwa disiplin adalah hal yang menyatu dalam diri seseorang dan menjadi bagian hidup yang muncul pada pola tingkah lakunya sehari-hari.

Berdasarkan hasil penelitian yang dilakukan oleh Roshita (2014) dengan judul meningkatkan kedisiplinan siswa melalui bimbingan kelompok dengan teknik modeling 
bahwa pelaksanaan layanan bimbingan kelompok dengan Teknik modeling dapat meningkatkan kedisiplinan berpakaian siswa dengan skor rata-rata 3,6.

Berdasarkan dari hasil analisis Daftar Cek Masalah (DCM) kelas X SMK 01 Muhammadiyah Semarang dapat disimpulkan sebagai berikut: peraturan sekolah terlalu menekan saya $(41,5 \%)$, saya sering terlambat $(37,7 \%)$, saya belajar tidak teratur waktunya $(41,5 \%)$, saya belajar hanya waktu siang hari $(49,1 \%)$, saya belajar kalau ada ulangan $(34,0 \%)$. wawancara peneliti dengan guru BK pada tanggal 3-7 September 2018 menyatakan bahwa kedisiplinan siswa kurang, masih banyak ditemukan siswa membolos, terlambat, banyak perilaku menyimpang yang terjadi di dalam sekolah maupun diluar sekolah. Hal ini berarti masih ada siswa yang kurang disiplin.

Dari data tersebut, diperlukan layanan Bimbingan dan Konseling yang dapat mengembangkan sikap disiplin sisiwa, dengan tujuan tercapainya prestasi siswa baik akademik maupun non akademik serta mentaati tata tertib sekolah. Salah satu layanan Bimbingan Dan Konseling yang mampu mengatasi permasalahan tersebut adalah layanan bimbingan kelompok. Bimbingan kelompok ini sangat efektif dalam mengembangkan sikap disiplin yang baik. Bimbingan Kelompok adalah layanan yang diberikan dalam situasi kelompok, Kegiatan bimbingan kelompok mampu memberikan informasi yang bisa diterima bagi anggota kelompok (Prayitno, 2013:309). Mengatasi permasalahan tersebut maka Teknik modeling dalam bimbingan kelompok diharapkan mampu membantu menyelesaikan khasus kedisiplinan di SMK 01 Muhammadiyah Semarang.

Modeling simbolik adalah bentuk teknik yang memberikan layanan dengan menggunakan media, media yang di pakai antara lain media film media cetak, setelah siswa mengamati media film dan media cetak tersebut siswa dapat mendemonstrasikan apa yang telah diamati dari media yang ditampilkan sehingga lebih efektif dalam mengembangkan sikap disiplin sisiwa. Lilis (2002:52),menjelaskan modeling simbolik adalah prosedur yang dilakukan dengan menggunakan media berupa film, video, buku pedoman, dll dengan cara memperagakan perilaku yang dikehendaki atau hendaknya dimiliki oleh klien.

Berdasarkan latar belakang tersebut penelitian ini berjudul "Pengaruh Layanan Bimbingan Kelompok dengan Teknik Modelling Simbolik Untuk Mengembangkan Kedisiplinan Siswa Kelas X SMK 01 Muhammadiyah Semarang".

\section{Metode}

Penelitian ini menggunakan metode true experiment design dengan model pretestposttest control group design, dengan adanya pretest dan posttest untuk mengetahui keadaan awal dan akhir kelompok eksperimen dan kelompok kontrol. Penelitian ini dilaksanakan di SMK 01 Muhammadiyah Semarang. alasan peneliti melakukan penelitian di SMK 01 Muhammadiyah Semarang yaitu di SMK 01 Muhammadiyah Semarang ditemukan permasalahan kedisiplinan rendah. Pada siswa kelas $X$ penelitian dilaksanakan pada tanggal 9 Januari - Juni 2019 pada sampel yang diambil secara rendom pada kelas $\mathrm{X}$ semester I tahun ajaran 2018/2019 dengan rincian menyusun proposal penelitian, penyusunan instrument penelitian, persiapan penelitian, melaksanakan penelitian ekperimen, menyusun hasil penelitian, dan penyempurnan.

Populasi dalam penelitian ini adalah siswa kelas X SMK 01 Muhammadiyah Semarang. dalam penelitian ini pengambilan sampel dilakukan dengan teknik sampling cluster random sampling, yaitu pengambilan dilakukan secara rendom di dapatkan 30 siswa kelas $X$

Teknik pengumpulan data yang digunakan dalam penelitian ini skala kedisiplinan digunakan untuk membandingkan skor sebelum mendapat perlakuan dengan setelah mendapat perlakuan mengalami peningkatan atau tidak.

Instrumen yang digunakan adalah sebuah skala psikologis, hasil uji coba dianalisis untuk mengetahui validitas, reliabilitas. Dari 32 item pernyataan terdapat 28 item pernyataan yang valid.

Analisis data yang dilakukan pada penelitian ini terdiri dari data awal dan data akhir. Analisis data awal dapat dilihat dari pretest sebelum diberi perlakuan menggunakan layanan bimbingan kelompok dengan teknik Modelling simbolik sudah dinormalitaskan dengan 
menggunakan uji lilifors. Kemudian untuk mengetahui pengaruh layanan bimbingan kelompok dengan teknik modelling simbolik digunakan hipotesis Uji t dan Uji-t.

\section{Hasil dan Pembahasan}

Perhitungan uji normalitas pada penelitian ini menggunakan uji lillifors dengan taraf signifikan $5 \%$. Kriteria dalam uji normalitas ini adalah jika $L 0<L_{\text {tabel }}$ maka data berdistribusi normal, sedangkan jika 0,134 $<0,22$ pada kelompok eksperimen dan 0,190<0,22 maka data berdistribusi normal. Berikut rekapitulasi hasil perhitungan normalitas awal data sampel berikut.

Tabel 1. Uji Normalitas Data Awal (Pretest) Kemampuan Kedisiplinan

\begin{tabular}{lccc}
\hline \multicolumn{1}{c}{ Kelas } & Lo & Ltabel & Kesimpulan \\
\hline Eksperimen & 0,134 & 0,22 & Berdistribusi normal \\
Kontrol & 0,190 & 0,22 & Berdistribusi normal \\
\hline
\end{tabular}

Berdasarkan tabel 1 terlihat bahwa hasil perhitungan yang diperoleh dari nilai pretest, maka berdasarkan uji normalitas diperoleh $\mathrm{Lo}_{0}<\mathrm{L}_{\text {tabel }}$ yaitu $0,134<0,22$ pada kelompok eksperimen dan $0,190<0,22$ pada kelompok kontrol pada signifikan $5 \%$ dengan $\mathrm{N} \mathrm{15}$, maka Ho diterima, Sehingga dapat disimpulkan bahwa data pretest kemampuan kedisiplinan berdistribusi normal.

\section{Data Akhir}

Perhitungan uji normalitas pada penelitian ini menggunakan uji lilifors dengan taraf signifikan $5 \%$. Kriteria uji normalitas ini adalah jika $L o<L_{\text {tabel }}$ maka data berdistribusi normal. Berikut rekapitulasi hasil perhitungan normalitas awal data sampel berikut :

Tabel 2. Uji Normalitas Data Akhir (Posttest) Kemampuan kedisiplinan

\begin{tabular}{lccc}
\hline \multicolumn{1}{c}{ Kelas } & Lo & Ltabel & Kesimpulan \\
\hline Eksperimen & 0,214 & 0,22 & Berdistribusi normal \\
Kontrol & 0,182 & 0,22 & Berdistribusi normal \\
\hline
\end{tabular}

Berdasarkan tabel 2 terlihat bahwa hasil perhitungan yang diperoleh dari skor posttest, maka berdasarkan uji normalitas diperoleh $\mathrm{Lo}<\mathrm{L}_{\text {tabel }}$ berdasarkan hasil post-test yaitu 0,214 $<0,22$ pada kelompok eksperimen dan 0,182 < 0,22 pada kelompok kontrol pada signifikan $5 \%$ dengan N 15, maka Ho diterima, Sehingga dapat disimpulkan bahwa data post-test kemampuan kedisiplinan berdistribusi normal.

Uji hipotesis peneliti menggunakan yaitu Uji $t$ dengan teknik analisis $t$ tes untuk menguji nilai pretest diperoleh hasil $\mathrm{t}_{\text {hitung }} 0,581>\mathrm{t}_{\text {tabel }} 2,131$. Dapat disimpulkan bahwa tidak ada perbedaan kemampuan regulasi diri siswa antara kelompok eksperimen dan kelompok kontrol.

Hipotesis kedua yaitu uji-t test yang bertujuan untuk mengetahui seberapa besar pengaruh antara rata-rata pretest dan rata-rata posttest. Dari hasil perhitungan uji t-test diperoleh hasil $t_{\text {hitung }} 4,89>\mathrm{t}_{\text {tabel }}$ 2,131 maka Ho ditolak dan Ha diterima jadi dapat disimpulkan bahwa ada pengaruh layanan bimbingan kelompok dengan Teknik modelling simbolik untuk meningkatkan kedisiplinan siswa kelas X SMK Muhammadiyah Semarang karena memiliki perbedaan yang signifikan dilihat dari hasil perhitungan uji t.

\section{Simpulan dan Saran}

Berdasarkan hasil analisis dan pembahasan hasil bahwa layanan bimbingan kelompok dengan teknik modelling simbolik mengalami peningkatan terhadap kemampuan 
kedisiplinan siswa kelas X SMK 01 Muhammadiyah Semarang. hal ini dapat dilihat pada hasil pretest dan posttest pada kelompok kontrol dengan rata-rata pretest mengalami selisih peningkatan sebanyak $34,715 \%$ sedang pada kelompok ekperimen yang diberikan layanan bimbingan kelompok dengan teknik modelling simbolik mengalami selisih peningkatan sebanyak 23,295 \% sehingga dapat disimpulkan bahwa layanan bimbingan kelompok dengan teknik modelling simbolik dapat meningkatkan kedisiplinan siswa kelas X SMK 01 Muhammadiyah Semarang.

\section{Daftar Pustaka}

Arikunto, Suharsimi. 2010. Prosedur Penelitian suatu Pendekatan Praktik. Jakarta: Rineka Cipta.

Damayanti. 2012. Buku Pintar Panduan Bimbingan dan Konseling. Yogyakarta:Araska

Djamarah, Syaiful Bahri \& Zain, Aswan. 2010. Strategibelajar mengajar. Jakarta: PT. Rineka Cipta.

Hamzah. 2008. Model Pelajaran "Menciptakan Proses Belajar Mengajar Yang Kreatif dan Efektif”. Jakarta: PT Bumi Aksara

Hartinah 2009. Konsep Dasar Bimbingan Kelompok. Bandung: PT Refika Aditama.

Hurlock, Elizabeth B. 2013. Perkembangan Anak Jilid 2. Jakarta: Erlangga.

Komalasari, Gantina, Eka Wahyuni, Karsih. 2011. Teori dan Teknik Konseling. Jakarta: Indeks.

Lewis. 2004. Dilema Kedisiplinan. Jakarta: PT Grasindo Widiasarana Indonesia

Lilis, Ratna. 2013. Teknik-Teknik Konseling. Yogyakarta: Budi Utama.

Maulana, Riki. 2016. Pengembangan model bimbingan kelompok berbasis islami untuk meningkatkan kecerdasan sosial siswa SMK . Jurnal Psikologi Pendidikan \& Konseling Volume 2 Nomor 1 Juni 2016

Mugiarso, Heru, dkk. 2009. Bimbingan dan Konseling. Semarang: UPT UNNES Press.

Nurihsan, Ahmad Juantika. 2009. Strategi Layanan Bimbingan dan Konseling. Bandung: PT. Refika Aditama.

Nurikhsan, Achmad jentika. 2014. Bimbingan dan Konseling Dalam Berbagai Latar Kehidupan (edisi revisi). Bandung: Refika Aditama

Prayitno. 2013. Dasar-Dasar Bimbingan dan Konsling. Jakarta: Rineka Cipta.

Tulus. 2004. Peran Disiplin Pada Perilaku Dan Prestasi Siswa. Jakarta: Gramedia Widiasarana Indonesia.

Rintyastini.2006. Bimbingan dan Konseling 2. Jakarta:Erlangga.

Roshita. 2014. Meningkatkan Kedisiplinan Siswa Melalui Layanan Bimbingan Kelompok dengan Teknik Modelling. Pekalongan: SMP Wonopinggono. Jurnal Penelitian Tindakan Kelas. Volume 16 Pada 17 April 2018. 
Soegeng. 2015. Dasar-dasar Penelitian. Yogyakarta : Magnum Pustaka Utama.

Sudjana. 2005. Metoda Statistika. Bandung: PT Tarsito.

Sugiyono. 2017. Metode Penelitian Kuantitatif Kualitatif dan R\&D. Bandung: Alfabeta.

Sukarno, Anton dan Venty. 2015. Statistik Pendidikan: Universitas PGRI Semarang.

Sukarno, Anton. 2008. Statistik Lanjut. Surakarta. UNS Press.

Sutanti, Tri . 2015. Efektivitas Teknik Modeling Untuk Meningkatkan Empati Mahasiswa Prodi Bk Universitas Ahmad Dahlan . Jurnal Psikologi Pendidikan \& Konseling Volume 1 Nomor 2 Desember 2015.

Tohirin. 2015. Bimbingan Dan Konseling Di Sekolah Madrasah (Berbasis Integrasi)Edisi Revisi. Jakarta: PT. Raja grafindo persada.

Wantah, Maria J. 2005. Pengembangan Disiplin Dan Moral Pada Anak Usia Dini. Jakarta: Direktorat jendral pendidikan tenaga perguruan tinggi. 